\title{
The Integration and Abstraction of EBS Models in Yucca Mountain Performance Assessment
}

\author{
S. David Sevougian \\ Sandia National Laboratories, U.S.A. \\ Vivek Jain \\ Bechtel SAIC Inc., LLC., USA \\ Abraham Van Luik \\ U.S. Department of Energy, U.S.A.
}

MOL . 20061026.0022

\section{INTRODUCTION}

The safety strategy for geological disposal of radioactive waste at Yucca Mountain relies on a multibarrier system to contain the waste and isolate it from the biosphere. The multi-barrier system consists of the natural barrier provided by the geological setting and the engineered barrier system (EBS). In the case of Yucca Mountain (YM) the geologic setting is the unsaturated-zone host rock, consisting of about 600 meters of layered ash-flow volcanic tuffs above the water table, and the saturated zone beneath the water table. Both the unsaturated and saturated rocks are part of a closed hydrologic basin in a desert surface environment. The waste is to be buried about halfway between the desert surface and the water table. The primary engineered barriers at YM consist of metal components that are highly durable in an oxidizing environment. The two primary components of the engineered barrier system are highly corrosion-resistant metal waste packages, made from a nickel-chromiummolybdenum alloy, Alloy 22, and titanium drip shields that protect the waste packages from corrosive dripping water and falling rocks.

Design and performance assessment of the EBS requires models that describe how the EBS and near field behave under anticipated repository-relevant conditions. These models must describe coupled hydrologic, thermal, chemical, and mechanical (THCM) processes that drive radionuclide transport in a highly fractured host rock, consisting of a relatively permeable network of conductive fractures in a setting of highly impermeable tuff rock matrix. An integrated performance assessment of the EBS must include a quantification of the uncertainties that arise from (1) incomplete understanding of processes and (2) from lack of data representative of the large spatial scales and long time scales relevant to radioactive waste disposal (e.g., long-term metal corrosion rates and heterogeneities in rock properties over the large $5 \mathrm{~km}^{2}$ emplacement area of the repository).

A systematic approach to EBS model development and performance assessment should include as key elements: (1) implementation of a systematic FEPs approach, (2) quantification of uncertainty and variability, (3) sensitivity analyses, and (4) model validation and limitations. The approaches used for these key elements in the Yucca Mountain repository program are described in Section 2 of this paper. A specific example of Yucca Mountain EBS model development and integration, related to the modeling of localized corrosion of Alloy 22, is discussed in Sections 3 and 4.

\section{KEY ELEMENTS OF EBS MODEL DEVELOPMENT AND PERFORMANCE ASSESSMENT}

\subsection{Features, Events and Processes (FEPs) and Scenario Implementation Methodology}

FEP analysis and scenario development follows a five-step approach:

Step 1. Identify and classify FEPs potentially relevant to long-term system performance. 
Step 2. Screen FEPs using specified criteria (low probability, low consequence, and by regulation) to identify those that should be included in or excluded from the PA.

Step 3. Form scenario classes from the retained (included) FEPs, as appropriate.

Step 4. Screen the scenario classes using the same criteria applied to the FEPs to identify any scenario classes that can be excluded from the PA.

Step 5. Specify the implementation of the scenario classes in the computational modeling for the YM PA and document the treatment of included FEPs.

FEP analysis, consisting of Steps 1 and 2, is an iterative process based on site-specific information, design, and regulations. All FEPs screened in during the formal identification and screening for Step 1 and Step 2 are used in Step 3 for scenario development. In Step 3 the screened-in FEPs from Step 2 resulted in a nominal scenario class and three disruptive event scenario classes. The nominal scenario class represents all screened-in FEPs except those pertaining to igneous or seismic disruption. It includes all FEPs associated with conditions that are expected at Yucca Mountain. The nominal scenario class includes the most likely evolution of the repository system in 10,000 years. The disruptive event scenario classes are developed using combinations of screened-in FEPs from the nominal scenario class and those additional FEPs for igneous and seismic processes that have a low probability of occurrence, but greater than the screening probability criteria of one occurrence in 10,000 years (NRC 2001). The disruptive event scenario classes consist of an igneous scenario class, a seismic scenario class, and a scenario class for the combination of igneous and seismic events.

In Step 4 of the FEP analysis and scenario development process, scenario screening is used to identify scenario classes whose combined probability of occurrence (or consequence) is low enough to permit exclusion from the YM PA. This resulted in the screening out of the combined igneous-seismic scenario class based on low probability. Finally, in Step 5, the screened-in FEPs and scenario classes were implemented in the PA models and documented in a series of FEPs reports.

\subsection{Process Used for Quantification of Uncertainty}

Aleatory uncertainty refers to inherent unpredictability and randomness in the repository system and is considered to be irreducible. At Yucca Mountain, the major source of this uncertainty arises from the occurrence of disruptive events (i.e., those associated with igneous or seismic activity). For example, although additional study may be conducted to improve the characterization of aleatory uncertainty associated with igneous or seismic disruption, this uncertainty cannot be removed through such study. In YM EBS modeling, aleatory uncertainty associated with disruptive events is represented as one or more Poisson processes and the time of occurrence of an event is treated as a random variable that is sampled in a Monte Carlo representation of the uncertainty in future system performance.

Epistemic uncertainty arises from a lack of knowledge about FEPs, which can be reduced by additional testing and data collection. Epistemic uncertainty is addressed in the YM EBS modeling through the use of alternative conceptual models and the probabilistic treatment of the model parameters. When multiple alternative conceptual models are plausible, one of two courses of action can be taken: (1) carry forward the most conservative model (leading to an over-prediction of mean annual dose) or (2) apply a probability weighting to the models and carry all of them into the total system calculations. Parameter uncertainty is generally addressed through probability distributions for the uncertain parameters. In some cases, a single conservative value is used for an uncertain parameter when a full probability distribution is not available or warranted. However, in general, the EBS models rely on a full range of defensible and reasonable parameter distributions rather than extreme parameter values for the uncertain parameters. 
The suite of models in the EBS model must use uncertainty information from numerous sources. To maintain consistency in the interfaces among organizations providing data, the integration of models, the consistency, transparency, and traceability of documentation, and the technical basis for the uncertainty, a team approach has been used (BSC 2002). Two teams were established to integrate model uncertainty and parameter uncertainty. The three primary members of each team consisted of a team lead, a subject matter expert (SME), and a performance assessment analyst to assure integration.

\subsection{Types of Sensitivity Analyses}

The Yucca Mountain total system model represents the behavior of a complex system with hundreds of parameters. Within the model components, the interaction between these variables can be complex and possibly nonlinear. To provide insight into effects of parameter and model interactions, a sensitivity analysis provides a useful and structured framework for examining the results of probabilistic performance assessments by determining the sensitivity of the total system model results (e.g., dose) to the uncertainties and assumptions in model inputs.

Sensitivity analysis, in its simplest sense, involves quantification of the change in total system model output corresponding to a change in one or more of the model inputs. In the context of probabilistic models, however, sensitivity analysis takes on a more specific definition, namely, ranking and quantifying the contribution from individual input parameters to the uncertainty (the spread or variance) of model predictions (Helton 1993, Section 1, p. 327). This is sometimes referred to as global sensitivity analysis or uncertainty importance analysis to distinguish it from the classical (local) sensitivity analysis measures typically obtained as partial derivatives of the output with respect to inputs of interest.

In the context of the total system model, the goal of sensitivity analysis is to answer these questions:

- Which uncertain variables have the greatest impact on the overall uncertainty in probabilistic model outcomes?

- Are there any significant input-output relationships that are nonmonotonic?

- Which are the factors, if any, controlling the separation of model outcomes into high-annual dose and low-annual dose producing realizations?

Analysis of the system-level model results uses regression-based analyses, entropy-based analyses, and classification-tree-based analyses to answer these questions. The analyses are carried out using results from the probabilistic total system model calculations at fixed times. The randomly sampled inputs considered in each of the realizations are treated as independent variables and the outputs computed from these inputs (e.g., total system-level performance measures, such as annual dose to a receptor) are treated as dependent variables.

In the regression-based sensitivity analysis approach, the focus is on identifying input variables that have the highest correlation (or partial correlation) with the output of interest. However, the applicability of such techniques may be restricted in some cases because the concept of correlation is strictly applicable to monotonic relationships (Hofer and Krzykacz 1995). It is, therefore, useful to pose the sensitivity analysis problem in the general terms of identifying important nonrandom patterns of association. Determining the significance and strength of input-output association is facilitated by the information-theoretic concept of entropy, which provides a useful framework for the characterization of uncertainty (or information) in the univariate case, and redundancy (or mutual 
information) in the multivariate case. Mishra and Knowlton (2003) describe a methodology for global sensitivity analysis that combines the mutual information concept with a contingency table analysis.

Techniques such as stepwise rank regression and mutual information analysis, are useful for identifying key sensitive parameters if the outcome of interest is a continuous variable. When the problem involves categorical outcomes such as "pass" versus "fail," "fit" versus "misfit," etc., classification-tree-based methods provide a more efficient framework for determining what variables or interactions drive model results into particular categories (Breiman et al. 1998). The output from tree-based models is generally expressed in the form of a series of decision rules such as "IF $x_{1}<a$ AND $x_{2}>b$ THEN $y=$ pass." This is an attractive feature for global sensitivity analysis because the model building process can capture non-additive behavior as well as synergy effects between input variables. Mishra and Knowlton (2003) describe how the methodology can be adapted for global sensitivity analysis to identify key sensitive parameters in probabilistic models. In comparison, stepwise regression analysis is restricted to linear (or linearized) additive forms and mutual information analysis can only handle single input-output pairs.

Such analyses of the impacts of input uncertainties on model results are useful for model validation purposes. Confidence in a model can be generated if the variables identified as important in the uncertainty importance analyses turn out to be important from a phenomenological point of view. The use of a complementary suite of uncertainty importance analysis techniques also allows a more detailed examination of how uncertain inputs affect different ranges of the computed outcome, thus increasing confidence that the integrated model has been implemented and executed correctly.

\subsection{EBS Model Validation}

Validation of a computer model for a physical system involves a series of procedural activities designed to generate and enhance confidence in the model's conceptualization and results during and after model development. For Yucca Mountain EBS and system modeling, the validation/confidencebuilding activity is formalized in a quality assurance procedure, designated LP-SIII.10Q-BSC (DOE 2005a). There are two main categories of procedural activities: (1) those conducted during development of the model and (2) those conducted after development of the model. Figure 1 is a flow diagram indicating how these activities in LP-SIII.10Q-BSC are applied to the YM EBS model suite. There are two key points about the application of this validation procedure:

- The "EBS Model" (i.e., the "source term") is validated as part of overall system model validation

- The multiple EBS sub-models and abstractions used in the system model are each validated "independently" with representative inputs from other submodels; then they are coupled within the system model, which is validated as a whole.

The three during-development activities shown in Figure 1 are: (1) selection of input parameters and/or input data, and a discussion of how the selection proceșs builds confidence in the model; (2) a description of calibration activities, and/or initial boundary condition runs, and/or run convergences, and a discussion of how the activity or activities build confidence in the model; and (3) a discussion of the impacts of uncertainties on model results. For the EBS models and the total system model, calibration activities included stability tests to identify the appropriate number of realizations, timesteps, and spatial discretization. Also, impacts of uncertainties on model results were addressed with various stochastic uncertainty sensitivity analyses to investigate the effect of input parameters and model conceptualizations on radionuclide releases from the EBS or dose at the accessible environment (see Section 2.3). 
Figure 1. Yucca Mountain Procedural Model Validation Approach

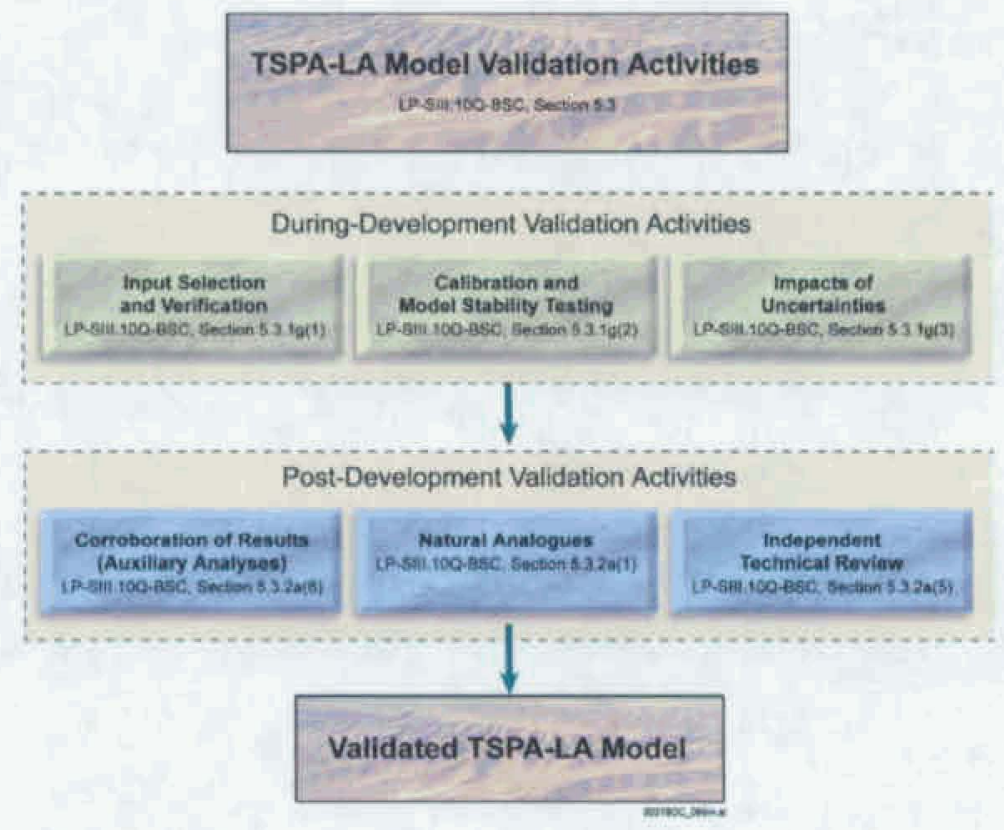

Post-development model validation activities described in the procedure include seven possible activities that may be used to validate models. For the system model, the required level of confidence and validation falls into the Level III validation category (DOE 2005b) that requires use of at least two of the post-development activities from LP-SIII.10Q-BSC. Three of the seven post-development activities listed in LP-SIII.10Q-BSC are the most appropriate for the total system model and associated EBS model suite. These include: (1) corroboration of model results with data acquired from the laboratory, field experiments, analogue studies, or other relevant observations not previously used to develop or calibrate the model (for the system model, only the analogue studies are applicable, since experiments over the appropriate spatial and temporal scales are not possible); (2) technical review by reviewers independent of the development, checking, and review of the model documentation; and (3) corroboration of the abstraction or system model results with results of auxiliary analyses to provide additional confidence in system model results ("auxiliary" analyses include, for example, sensitivity analyses to "stress" the models and/or detailed subsystem analyses).

\section{EXAMPLE OF EBS MODELING FOR YM: LOCALIZED CORROSION OF ALLOY 22}

\subsection{Description of the Localized Corrosion Process}

Alloy 22 (UNS N06022) is the reference material for construction of the outer barrier of the YM waste package (WP). This alloy consists, by weight, of 20.0 to $22.5 \%$ chromium, 12.5 to $14.5 \%$ molybdenum, $3.5 \%$ tungsten, 2.0 to $6.0 \%$ iron, $2.5 \%$ cobalt, and the balance nickel (i.e., about $50 \%$ nickel). The unusual localized corrosion resistance of Alloy 22 is mainly due to addition of molybdenum and chromium to the nickel base (Hack 1983). The passive-film oxides of $\mathrm{Cr}$ and Mo are very stable at low pH values, making Alloy 22 highly resistant to localized corrosion (LC). LC is a phenomenon in which corrosion progresses at discrete sites or in a nonuniform manner. The rate of LC penetration is generally higher than the rate of general (or uniform) corrosion penetration. For YM 
EBS modeling the dominant form of LC is conservatively assumed to be crevice corrosion rather then to pitting corrosion on boldly exposed surfaces.

The Alloy 22 outer barrier may experience a wide range of exposure conditions during its service life. Crevices may be formed on the waste package surface at occluded regions such as in between the waste package and its supports and potentially beneath mineral scales, corrosion products, dust, rocks, and biofilms. The area between the $50-\mathrm{mm}$ thick inner stainless steel vessel and the outer $20-\mathrm{mm}$ thick Alloy 22 vessel of each waste package could also be considered a creviced region after the outer layer is breached. The chemical environment in a creviced region may be more severe than the EBS near-field environment due to hydrolysis of dissolved metals in the creviced region. Metal ion hydrolysis can lead to the accumulation of hydrogen ions and a corresponding decrease in $\mathrm{pH}$. Electromigration of chloride ions (and other anions) into the crevice must occur to balance the charge within the creviced region (Jones 1992, Chapter 7), leading to a migration of positively charged metal ions (i.e., corrosion).

Localized corrosion of Alloy 22 is analyzed with two model components: an initiation model and a propagation model. In the initiation model, localized corrosion occurs when the open-circuit potential, or corrosion potential $\left(E_{\text {corr }}\right)$, is equal to or greater than a critical threshold potential ( $\left.E_{\text {critical }}\right)$, that is, $\Delta E\left(=E_{\text {critical }}-E_{\text {corr }}\right) \leq 0$. The magnitude of $\Delta E$ is an index of the localized corrosion resistance; i.e., the larger the difference, the greater the localized corrosion resistance. This conceptual model of localized corrosion initiation is widely accepted by the corrosion community and has been published extensively (e.g., Böhni 2000).

The temperature, $\mathrm{pH}$, chloride-ion concentration, and nitrate-ion concentrations in aqueous solutions on the waste-package outer surface are the primary environmental factors that determine the potential for initiating LC, i.e., in determining $E_{\text {corr }}$ and $E_{\text {critical }}$. These are obtained from the EBS ThermalHydrologic Environment Submodel and the EBS Chemical Environment Submodel (see Figure 2). LC requires the presence of a liquid water film on the WP surface. Two types of aqueous solutions may lead to environmental conditions conducive to LC initiation on the WP outer surface: (1) dripping crown seepage water that contacts the WP outer surface by gravity drainage through the crown of the emplacement tunnels, and (2) salt deliquescence in dust particles that may reside on the WP outer surface. LC resulting from salt deliquescence in dust particles has been screened out in the FEPs screening process, based on geochemical analyses, leaving crown seepage as the only viable source of potentially deleterious liquid.

The critical threshold potential $\left(E_{\text {critical }}\right)$ can be defined as a certain potential above which the current density or corrosion rate of Alloy 22 increases irreversibly above the general corrosion rate of the passive metal and, therefore, represents local breakdown of the passive film that would normally protect the material from crevice corrosion. Under environmental conditions promoting LC, $E_{\text {critical }}$ is the lowest potential that would trigger LC. The "true" value of $E_{\text {critical }}$ for a metal or alloy, for a given set of conditions, is considered to be the lowest potential at which the corrosion current, when held potentiostatically, does not decay with time and stays above the passive current density. After review of the different approaches to obtaining the critical potential for the initiation of LC, the crevice repassivation potential obtained from cyclic potentiodynamic polarization tests was selected as described in BSC 2004 . The crevice repassivation potential $\left(E_{\text {rcrev }}\right)$ is determined by evaluating the current as the electrochemical potential is continuously scanned from the open-circuit or corrosion potential following a relatively short period of exposure of the metal specimen to the environment. At the breakdown potential the current experiences a sharp increase, indicative of the breakdown of the passive film. The repassivation point is determined by reversing the potential scan and noting when 
the reverse current scan crosses the forward current scan. In the potential scan shown in Figure 3, the repassivation point/potential is designated as $E_{R}$.

Figure 2. Suite of EBS Models and Abstractions

(note: $\mathrm{DS}$ = drip shield; WP $\equiv$ waste package; THC $\equiv$ thermal-hydrologic-chemical; $\mathrm{UZ} \equiv$ unsaturated zone)

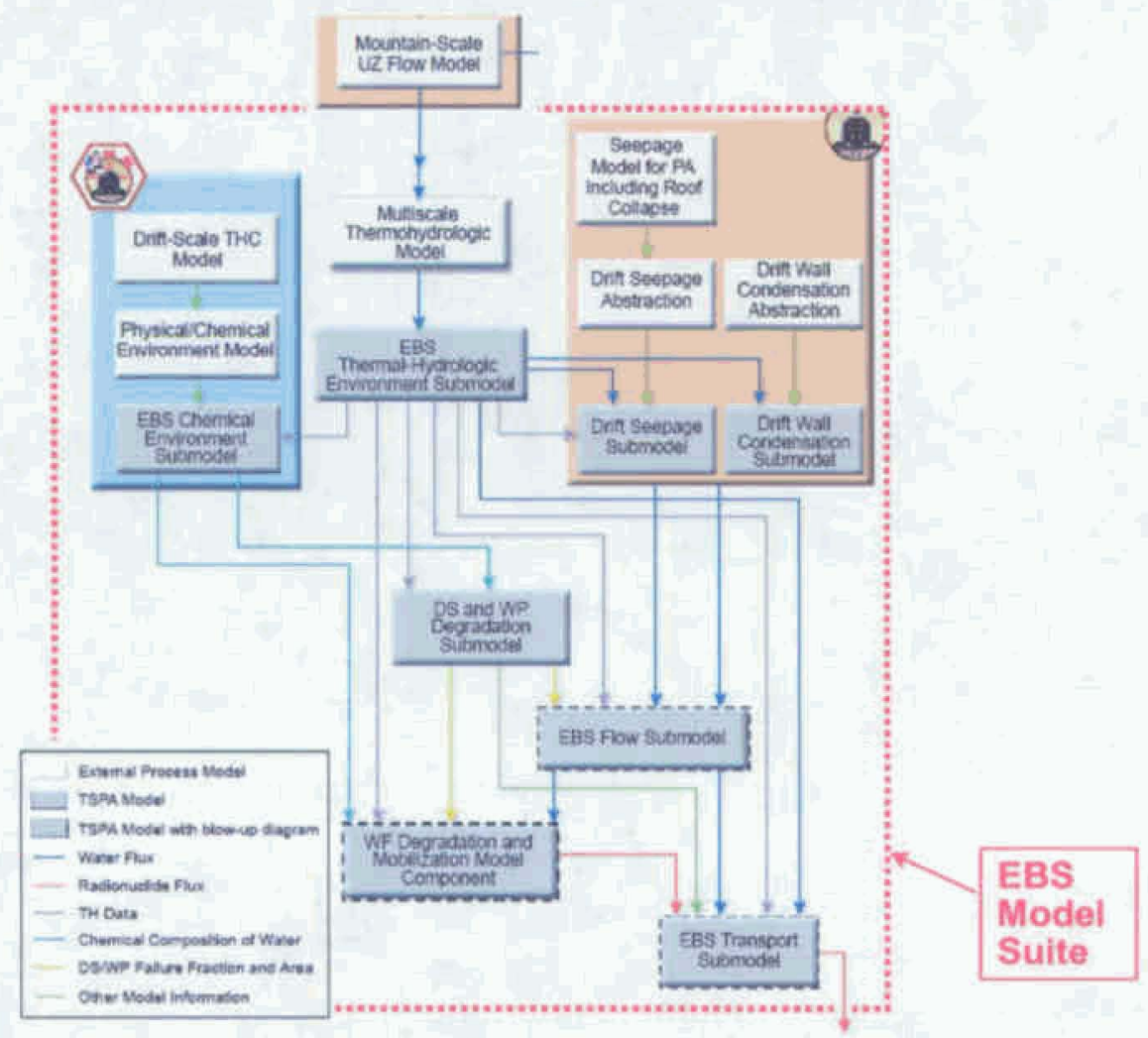

Figure 3. Example of a Cyclic Potentiodynamic Polarization Scan for Alloy 22 (after Payer 2004)

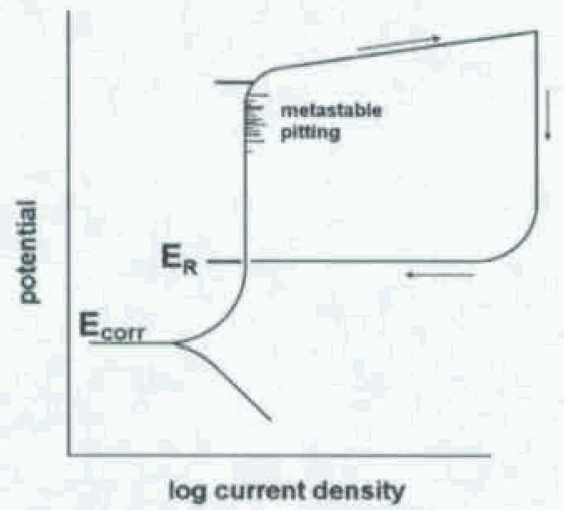

Using the crevice repassivation potential for the critical threshold potential, the condition for LC initiation is $\Delta E=E_{\text {nerey }}-E_{\text {coir }} \leq 0$. The model for $E_{\text {rerew }}$ was developed using a regression model fit to experimental long-term corrosion potential data (Estill 1998), as a function of the major 
exposure-environment variables: temperature, $\mathrm{pH}$, chloride ion concentration, and nitrate ion concentration. Based on the experimental data, the WP outer surface is not susceptible to crevice corrosion if the solution contacting the WP has a neutral to alkaline $\mathrm{pH}$ and contains high enough concentrations of inhibitive ions, such as nitrate. Alternatively, the WP outer surface is potentially susceptible to crevice corrosion if an acidic chloride-containing solution with relatively lower concentrations of inhibitive ions contacts the WP outer surface while it is at elevated temperature. Based on the available experimental data, the crevice repassivation potential, $E_{r c r e v}$ is expressed as (BSC 2004):

$$
E_{\text {rerev }}=E_{\text {rerev }}^{o}+\Delta E_{\text {rerev }}^{N O_{3}^{-}}
$$

where

$$
\begin{aligned}
& E_{\text {rcrev }}^{o}=\text { the crevice repassivation potential in the absence of inhibitive nitrate ions } \\
& \Delta E_{\text {rcrev }}^{N O_{3}^{-}}=\text {the crevice repassivation potential changes resulting from the inhibiting } \\
& \text { effect of nitrate in solution, where the nitrate ion concentration is } \\
& \text { considered to represent the effect of all inhibiting ions present in the } \\
& \text { solution contacting the waste packages in the repository. }
\end{aligned}
$$

$E_{\text {rcrev }}^{o}$ is defined in terms of WP surface temperature and chemical conditions as follows:

$$
E_{\text {rcrev }}^{o}=a_{o}+a_{1} T+a_{2} p H+a_{3} \log ([C l])+a_{4} T \log ([C l])
$$

where $a_{o}, a_{1}, a_{2}, a_{3}$, and $a_{4}$ are uncertain regression constants coupled with a covariance matrix, $T$ is the WP outer surface temperature $\left({ }^{\circ} \mathrm{C}\right), \mathrm{pH}$ is the negative log of the hydrogen ion activity, and $\left[\mathrm{Cl}^{-}\right]$is the chloride ion molality (moles $/ \mathrm{kg}$ water).

The effect of nitrate ion concentration on the crevice repassivation potential is represented as

$$
\Delta E_{r c r e v}^{N O_{-}^{-}}=b_{o}+b_{1}\left[\mathrm{NO}_{3}^{-}\right]+b_{2} \frac{\left[\mathrm{NO}_{3}^{-}\right]}{\left[\mathrm{Cl}^{-}\right]}
$$

where $b_{o}, b_{l}$, and $b_{2}$ are constants, $\left[\mathrm{NO}_{3}^{-}\right]$is the nitrate ion molality (moles $/ \mathrm{kg}$ water), and $\left[\mathrm{Cl}^{-}\right]$is the chloride ion molality. As indicated in the above equation, the effect of the interaction of the competing aggressive chloride ions and the inhibitive nitrate ions on the crevice repassivation potential is represented through the ratio of the concentrations of the two competing ions and the concentration of the nitrate ion, where the ratio term is limited to a value of 0.5 .

The long-term steady-state corrosion potential, $E_{\text {corr }}$, for the WP outer surface is expressed as

$$
E_{\text {corr }}=c_{o}+c_{1} T+c_{2} p H+c_{3}\left[\mathrm{Cl}^{-}\right]+c_{4} \log \left(\frac{\left[\mathrm{NO}_{3}^{-}\right]}{\left[\mathrm{Cl}^{-}\right]}\right)
$$

where $c_{o}, c_{1}, c_{2}, c_{3}$, and $c_{4}$ are uncertain regression coefficients of the parameters, and the other parameters are as previously defined.

Figure 4 shows an example of the predictions of this regression model, and the associated uncertainty for a representative brine. It can be seen $\Delta E \leq 0$ only occurs at very high temperatures, which are only present during the early thermal phase after waste emplacement (as shown in Figure 6 below). 
The other model component of localized corrosion, as mentioned above, is the propagation model. For Yucca Mountain EBS modeling a conservative model is used, which assumes a constant (timeindependent) penetration rate after LC is initiated. This constant penetration rate is sampled from the epistemic uncertainty distribution for the LC rate. Although the LC rate is modeled as time invariant, the crevice corrosion propagation rate would be expected to decrease with time and increasing depth of the crevices under realistic conditions.

Figure 4. Model Results for Crevice Corrosion Susceptibility of the Waste Package Outer Barrier (Alloy 22) as a Function of Temperature for $10 \mathrm{~m}$ chloride, $\mathrm{pH} 7$, and $1.5 \mathrm{~m}$ nitrate (BSC, 2004)

$E_{\text {terev }}$ and $E_{\text {torr }}$ vs. Temperature

(10 $\mathrm{m} \mathrm{Cl}$. PH 7. and $1.5 \mathrm{~m} \mathrm{NO_{3 }}$ : $\mathrm{NO}_{5} / \mathrm{Cl}_{\text {Ratio }}=0.15$ )

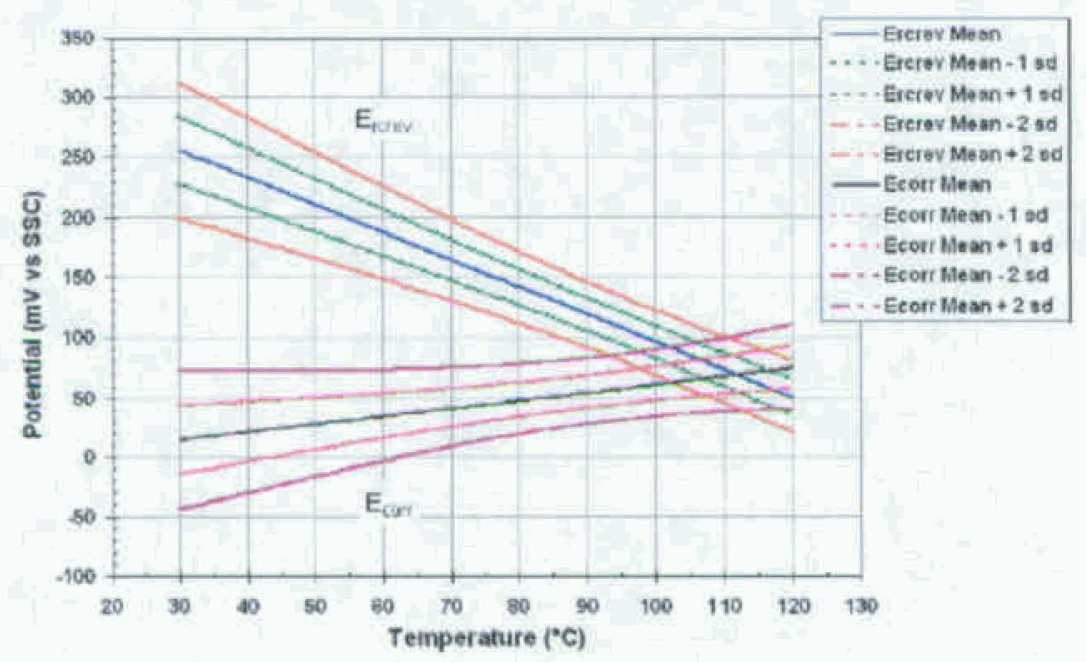

\subsection{Abstraction and Modeling Methodology}

For a 10,000-year time period, localized corrosion modeling is included only in the seismic scenario class because in the nominal scenario class the titanium drip shields, which protect the Alloy 22 waste packages from seeping water and rockfall, remain intact and divert all crown seepage water.

As illustrated on Figure 5, the key EBS coupled submodels for localized corrosion include:

- EBS Chemical Environment Submodel: Used for evolution of $\mathrm{PCO}_{2}$ in the gas phase and evolution of the dissolved ion concentrations (e.g., nitrate, chloride, $\mathrm{pH}$ ) in the liquid phase of the seepage water dripping onto the waste package. These evolve in response to the thermal decay pulse from the hot waste packages.

- Drift Seepage Submodel: Used to determine the magnitude and location of seepage water entering the emplacement tunnels.

- EBS Thermal-Hydrology (TH) Environment Submodel: Provides time-dependent values for temperature and relative humidity on WP surfaces and drift-wall temperature. The abstraction also provides time-dependent adjusted values that are used to correct temperature and relative 
humidity values for the insulating effect of rubble caused by drift degradation induced by seismic ground motion.

- LC Initiation Abstraction. Determines $\Delta E$ as a function of time based on the chemical and thermal time histories, and subsequently outputs an indicator variable, $I$, to record whether a waste package has a favorable $(I=1)$ or unfavorable $(I=0)$ environment for localized corrosion initiation.

Figure 5. Coupling of EBS Localized Corrosion Initiation Model with Environmental Input Models and Abstractions

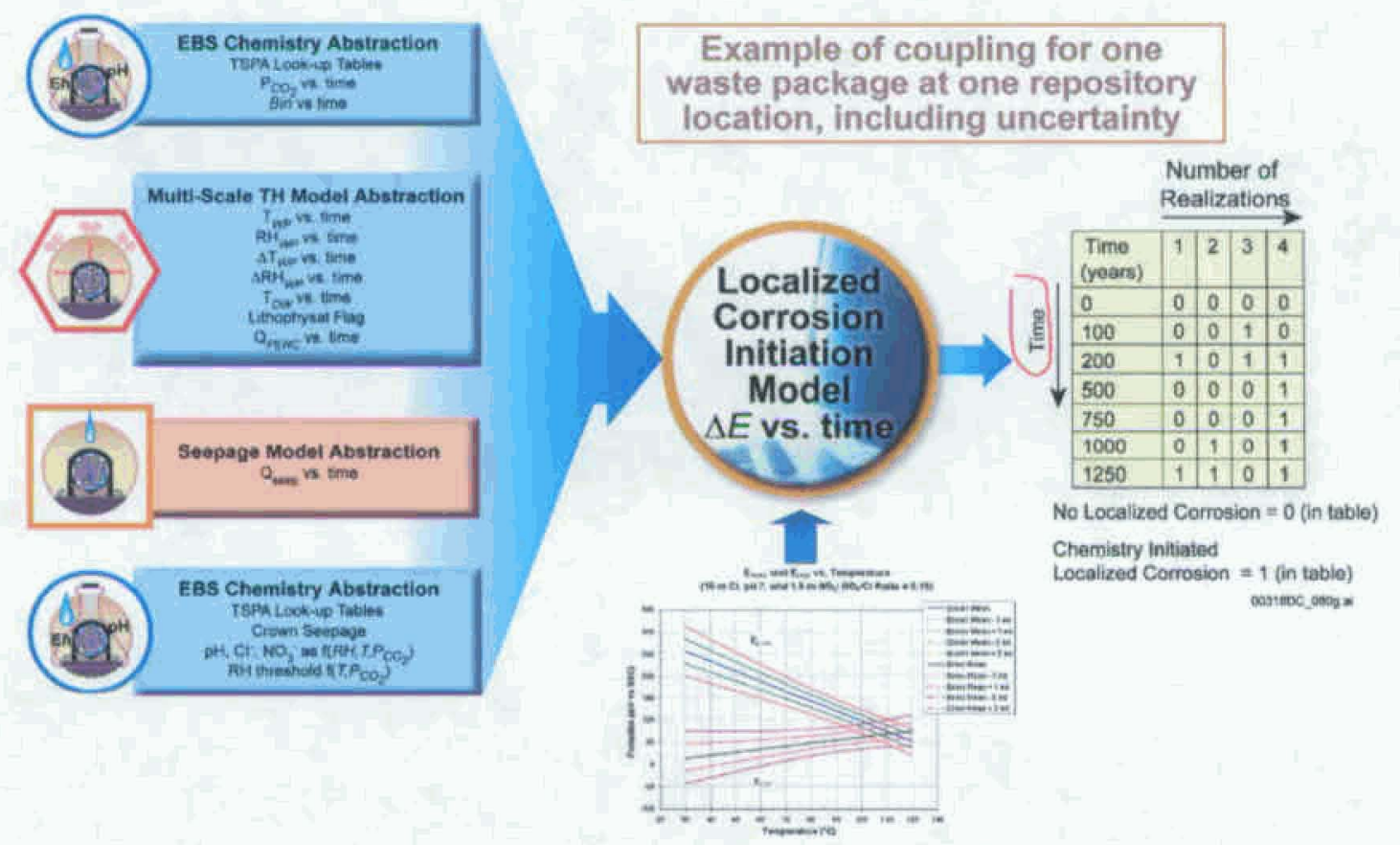

The most important of the previously listed submodels is likely the TH model, since the temperature excursion caused by the radioactive decay heat controls the chemical regimes through which the system passes. It drives liquid and vapor transport of the pore water, causing boiling and mineral precipitation, which causes significant changes to the chemical composition of the water seeping into the waste emplacement tunnels. This is best illustrated by Figure 6, showing five major chemical regimes, of which Period IV is the only one that might have conditions favorable to the occurrence of localized corrosion. The five regimes for a "medium temperature" waste package are:

- I- Preclosure and emplacement of waste packages (0 to $50 \mathrm{yrs})$

- II - Heat up after closure (about 50 to 65 yrs)

- III - Cool-down/thermal barrier: drift wall above boiling temperature (about 65 to $750 \mathrm{yrs}$ )

- IV - Cool-down/post-thermal barrier: dripping and seepage possible (about 750 to $1375 \mathrm{yrs}$ )

- V - Waste packages below critical temperature for localized corrosion ( >1375 yrs) 


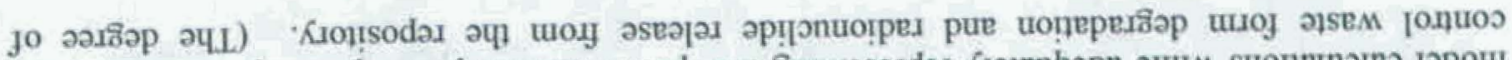

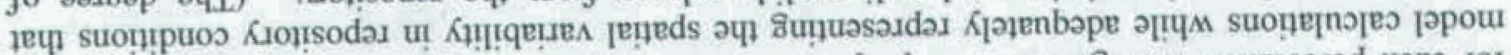

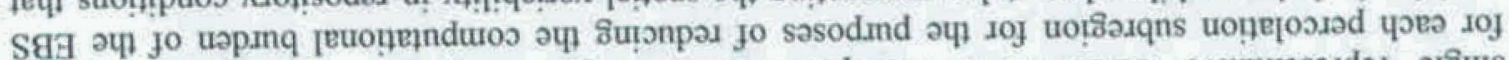

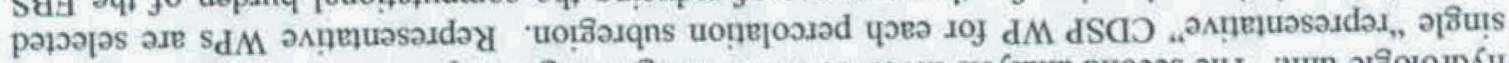

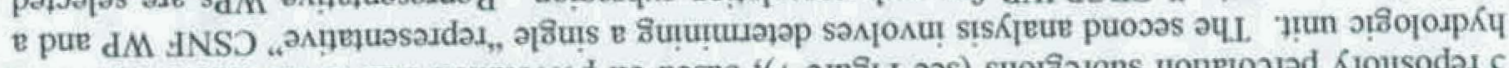

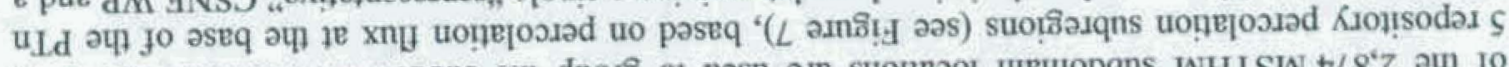

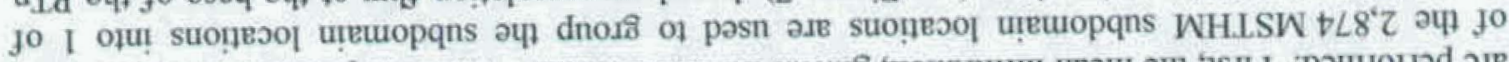

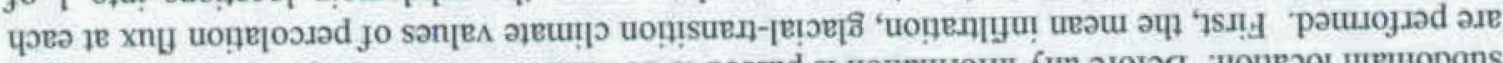

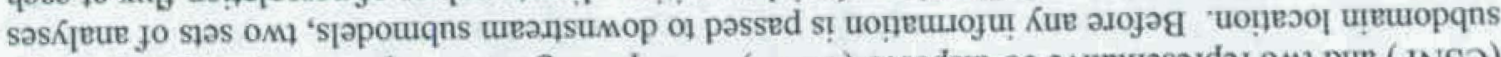

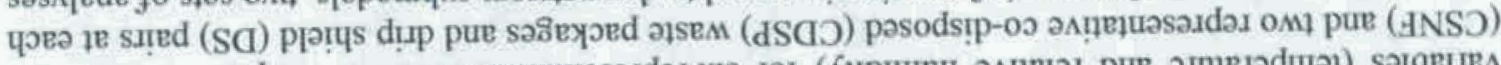

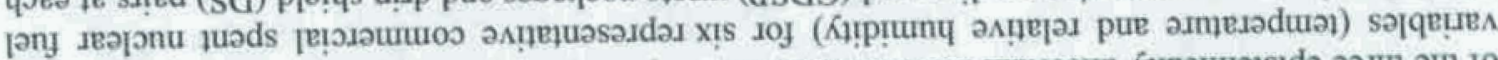

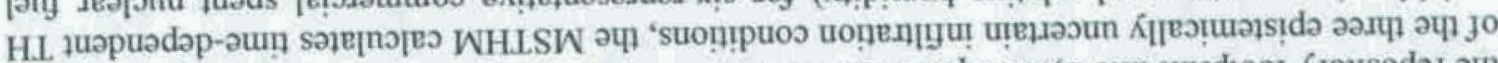

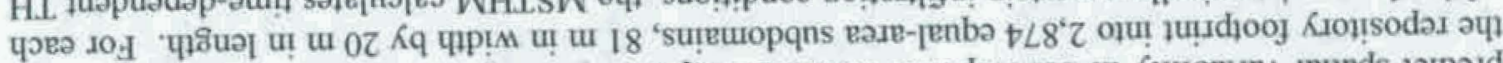

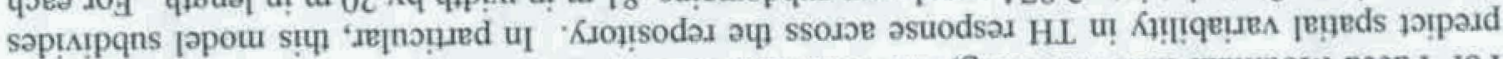

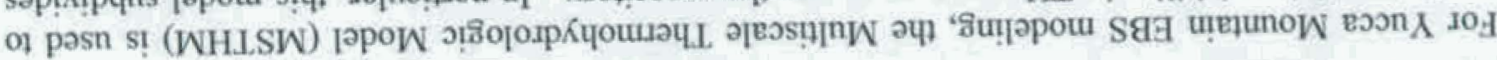

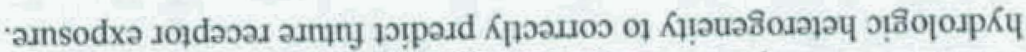

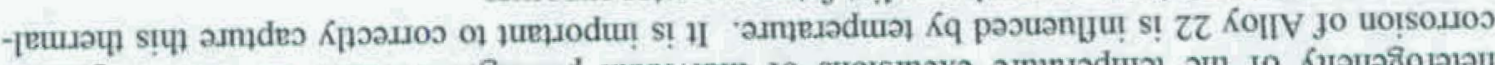

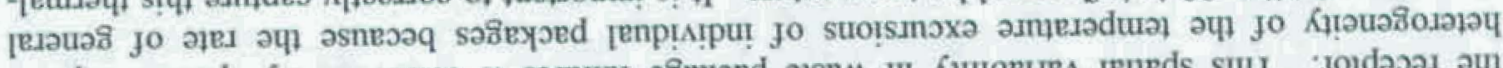

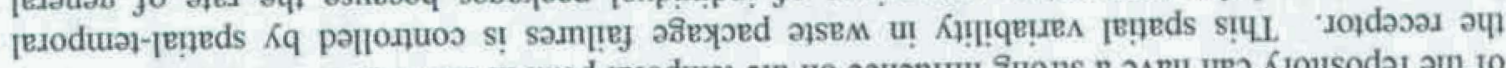

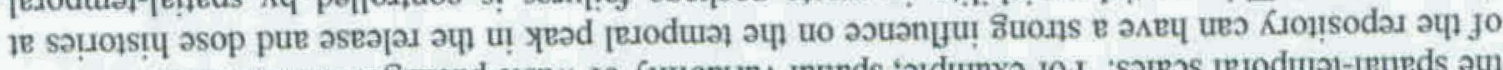

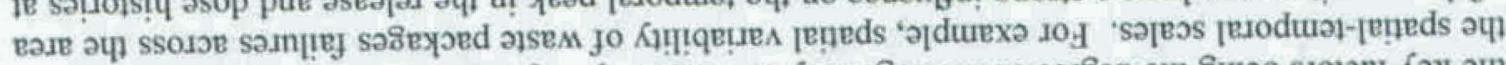

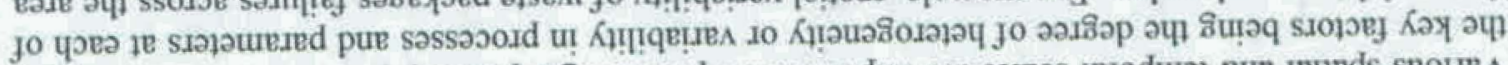

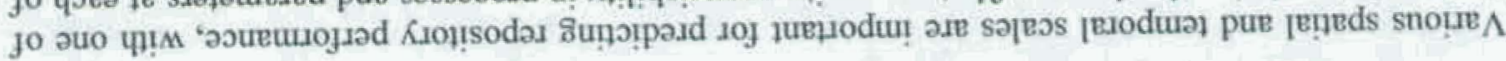

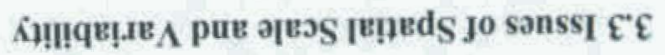

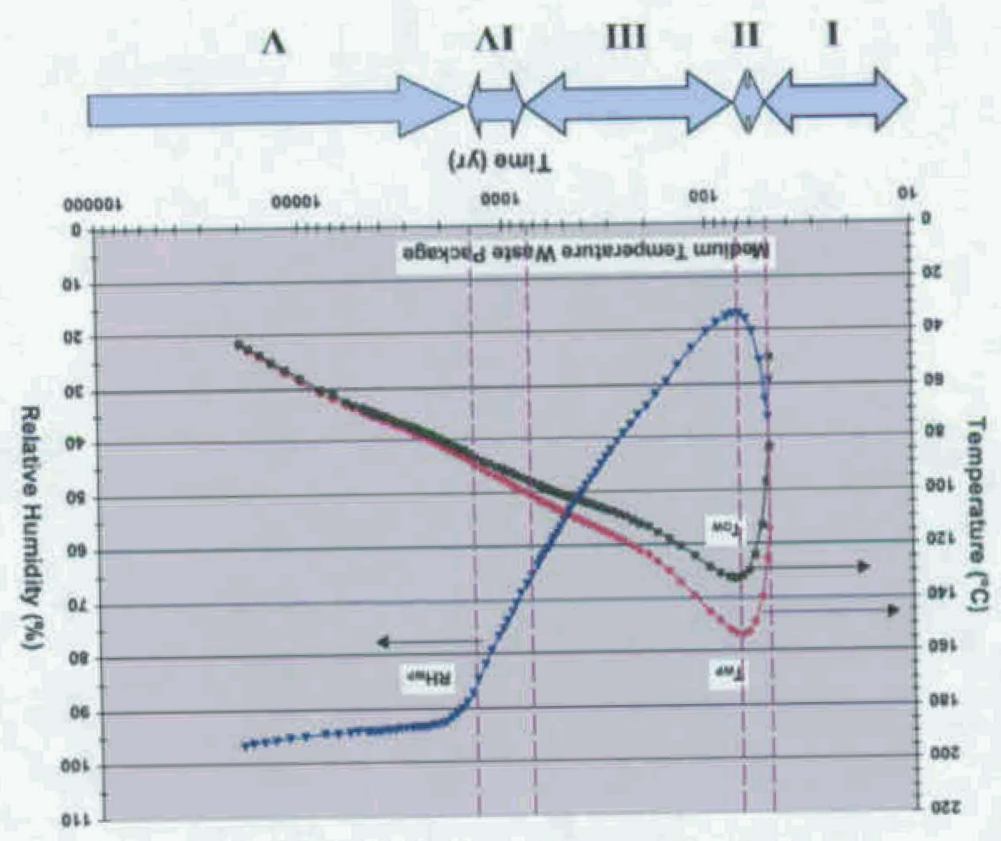

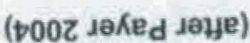

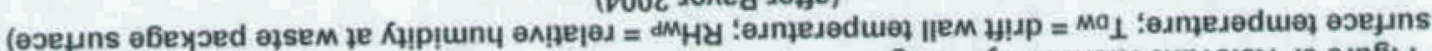

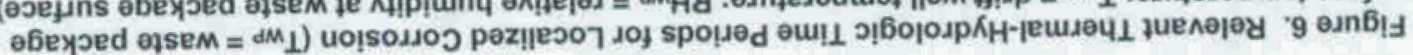


variability necessary to model the latter two processes is much less than the variability required for waste package failure processes.)

Figure 7. Spatial Scales and Levels of Discretization in the TSPA EBS Model Suite

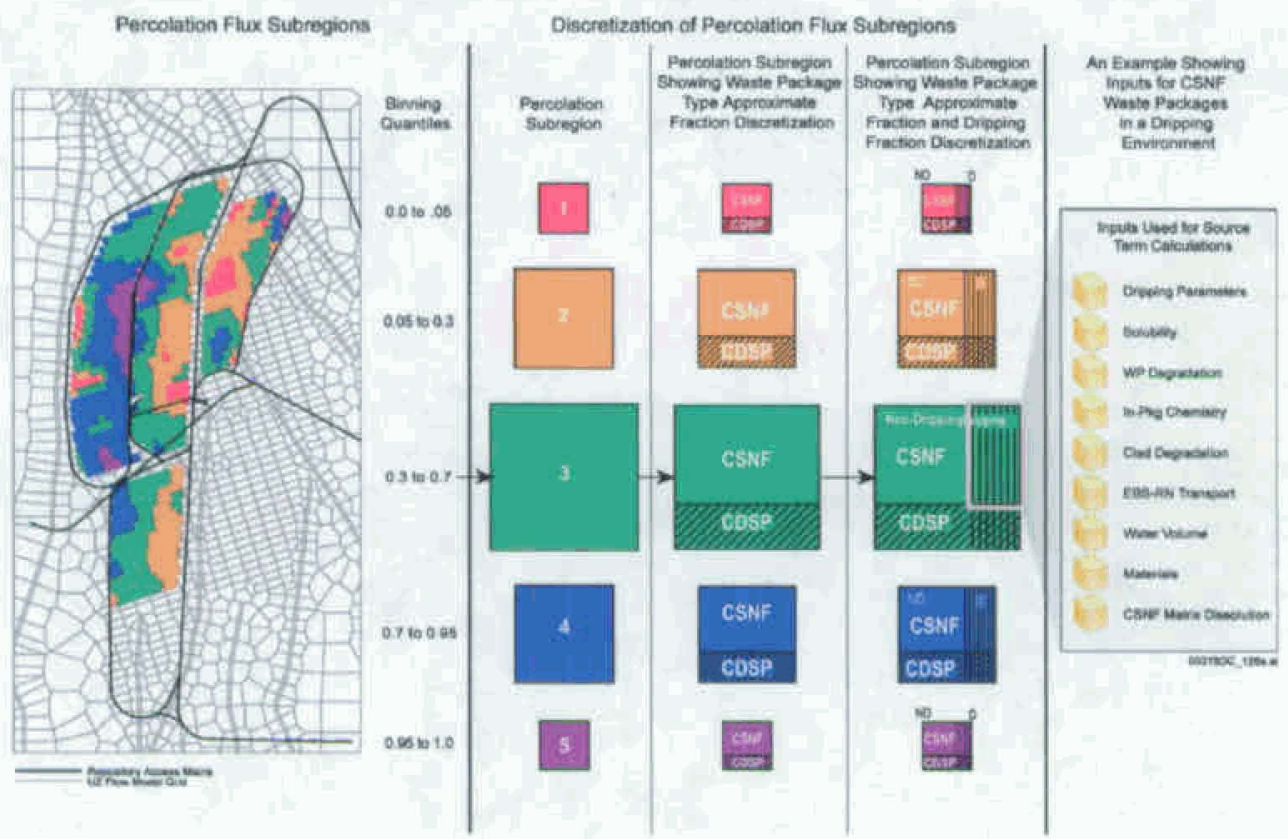

\subsection{Coupling and Integration of Models}

Section 3.2 (see Figure 5) showed how various EBS submodels are coupled to model localized corrosion initiation on a single waste package. In the present section, Figure 8 illustrates the steps taken to model localized corrosion on multiple waste package in various environments in the YM EBS performance assessment model. The LC Initiation Analysis described here includes two computational loops for including uncertainty: an outer epistemic uncertainty loop, and an inner aleatory uncertainty loop. In the outer loop, epistemic uncertainties associated with LC initiation, chemical environment on the WP outer surface, drift seepage, and rubble (natural backfill caused by a strong ground motion seismic event) are sampled using Monte Carlos sampling for each LC realization. These epistemic uncertainties include:

- Ten uncertain coefficients in the LC Initiation Abstraction, viz, the linear regression fitting parameters $\left(a_{0}, a_{1}, a_{2}, a_{3}, a_{4}, c_{0}, c_{1}, c_{2}, c_{3}\right.$, and $\left.c_{4}\right)$ associated with the crevice repassivation potential and the long-term steady-state corrosion potential, discussed in Section 3.1.

- Seven parameters that quantify the uncertain evolution of the chemical environment on the WP outer surface, e.g., $\mathrm{PcO}_{2}$, nitrate/chloride ratio, and $\mathrm{pH}$.

- Six uncertain drift-seepage parameters, including epistemic uncertainty in fracture permeability and capillarity.

A Monte Carlo sample set of sufficient size, $N_{L C}=100$, is used to evaluate the epistemic uncertainties. After the epistemic parameters are sampled, the simulation is broken into 50 different cases for modeling of aleatory uncertainty, with the Monte Carlo sample set applying equally to all 50 cases. These 50 cases are a combination of (1) coarse-scale spatial heterogeneity (the five percolation 
subregions shown in Figure 7); (2) five thermal-hydrologic cases representing coarsely discretized epistemic uncertainty in deep percolation flux and host-rock thermal conductivity (not sampled in the main Monte Carlo epistemic uncertainty loop); and (3) the bimodal packaging of the waste into CSNF (commercial spent nuclear fuel) packages and co-disposal packages (high level glass waste and defense spent nuclear fuel). Next, for each outer-loop realization $\left(R_{L C}=1,2, \ldots, N_{L C}\right)$ and for each of the 50 cases an inner loop over all the $N_{S L}$ locations in the percolation subregion is executed $\left(N_{S L}\right.$ is a subset of the 2874 subdomains in the MSTHM, e.g., Subregion 3, the largest of the five percolation subregions, encompasses 1100 of the 2874 subdomains). Aleatory uncertainties are sampled at each waste-package location in the inner loop. The aleatory uncertainties represent spatial variability in the parameters and they include:

- Temperature and relative humidity time histories associated with one of six CSNF WP time histories or one of two CDSP WP time histories at each of the 2874 subdomains

- Drift-seepage parameters including spatial variability of the flow focusing factor, fracture permeability, and capillarity at each of the 2874 subdomains

The output generated for the inner-loop is primarily the time histories of LC initiation (represented by a sequence of zeroes and ones as shown in Figure 5) due to the chemical evolution of crown seepage water on each of the $N_{S L}$ WPs in the percolation subregion.

Figure 8. Implementation and Connection of the Localized Corrosion Initiation Model, and Associated Uncertainties and Variabilities, into EBS and Total System Modeling

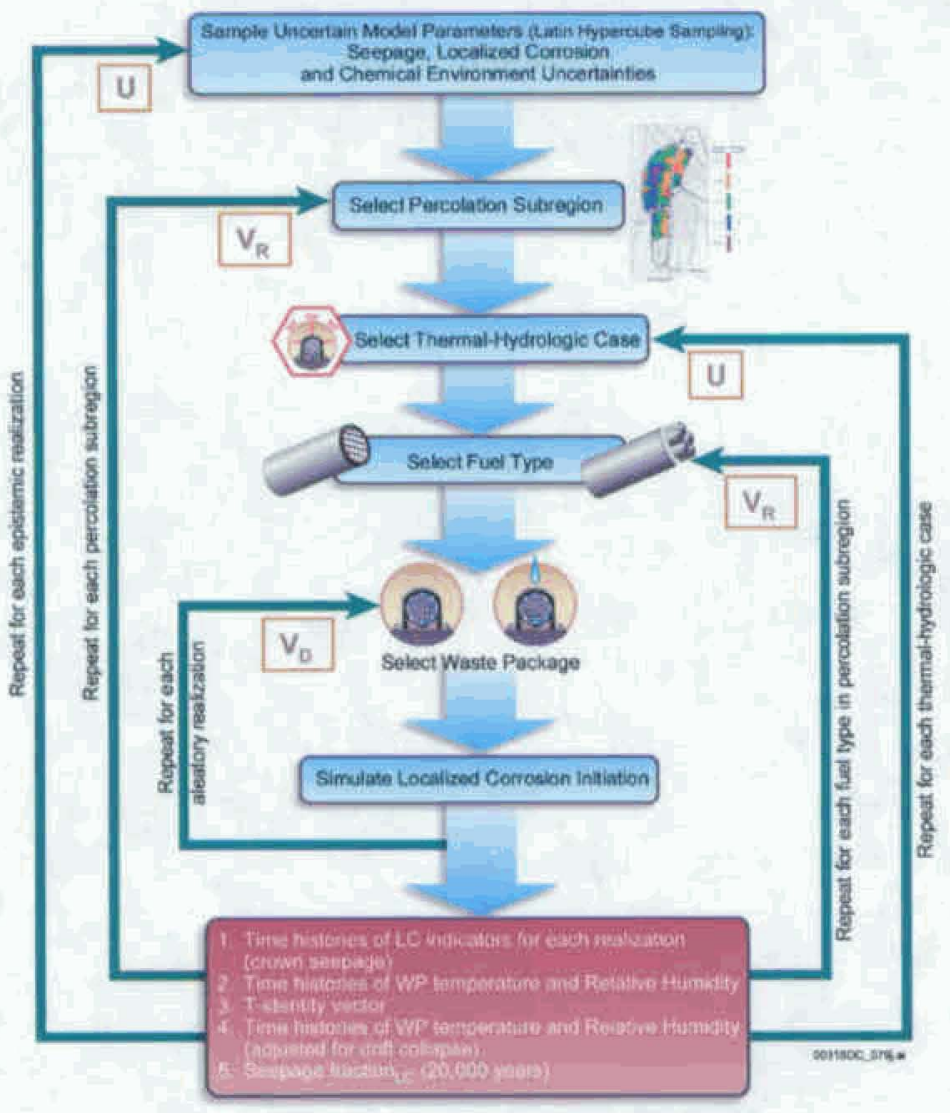

$$
\begin{aligned}
& \mathrm{U}=\text { uncertainty } \\
& \mathrm{V}_{\mathrm{R}}=\text { variability (representative } \\
& \quad \text { or upscaled) } \\
& \mathrm{V}_{\mathrm{D}}=\text { variability (detailed or } \\
& \text { fine-scale) }
\end{aligned}
$$




\subsection{Representative Results of the Localized Corrosion Model}

Figure 9 shows representative results of the integration of the various EBS environmental submodels as they affect the prediction of possible localized corrosion of the Alloy 22 outer waste package barrier. These results are for a hypothetical design where there is no titanium drip shield or where the titanium drip shield fails significantly earlier than its design lifetime. It is clear from the predictions in Figure 9 that Period IV chemistry is the only chemistry wherein the nitrate/chloride ratio is low enough to impact the corrosion potential.

Figure 9. Example Results of EBS Model Integration: Fraction of Waste Packages Failed by Localized Corrosion (assuming no drip shield protection)
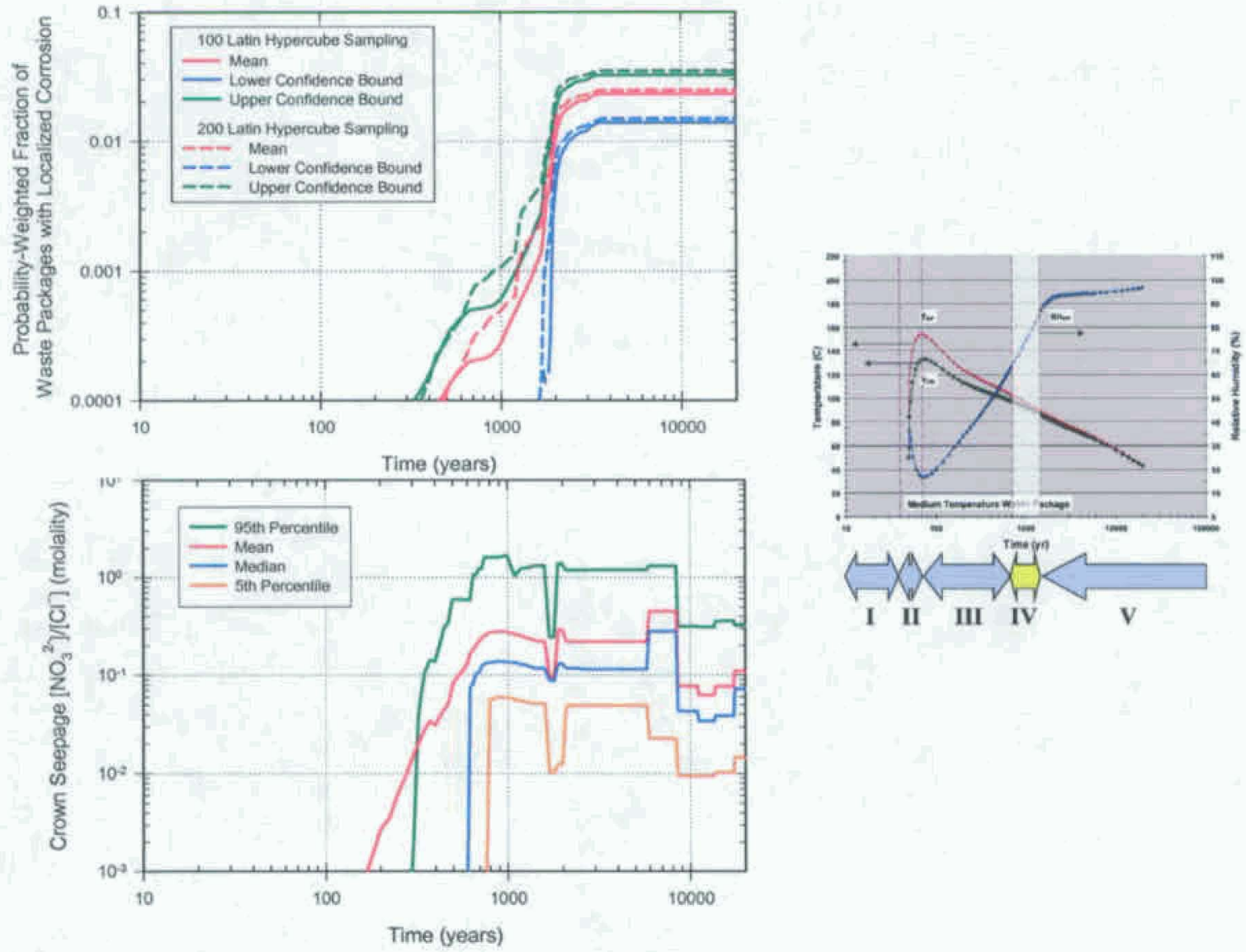

\section{SUMMARY}

For Yucca Mountain EBS and total system modeling, the use of systematic approaches for FEPs screening and uncertainty quantification builds confidence in the EBS Model and the associated PA. Validation via proceduralized approaches for individual components of the EBS model, as well as for the entire EBS model (as part of the TSPA model), builds confidence. A variety of complementary sensitivity and uncertainty analyses on model results is a key factor in the validation process and is critical to explaining model behavior. 
Varying degrees of abstraction, coupling, scaling, and quantification of uncertainty/variability have been used in Yucca Mountain EBS modeling, as appropriate to capture the primary effects of key processes. For example, detailed variability in thermal-hydrologic processes is necessary and appropriate for modeling the waste package failure history caused by localized corrosion processes, while representative variability in thermal-hydrologic processes is sufficient to capture waste-form degradation and mobilization processes.

\section{ACKNOWLEDGEMENTS}

We would like to thank other scientists on the Yucca Mountain Project for contributions to the text of this paper, including Kevin Mon, Srikanta Mishra, Peter Swift, Jon Helton, Cedric Sallaberry, Patrick Mattie, Bryan Bullard, Joe Payer, Bryan Dunlap, Pat Lee, Tom Buscheck, Jerry McNeish, Ralph Rogers, Debbie Miller et. al.

\section{REFERENCES}

Böhni, H. 2000. "Localized Corrosion of Passive Metals." Chapter 10 of Uhlig's Corrosion Handbook. Revie, R.W., ed. 2nd Edition. New York, New York: John Wiley \& Sons.

Breiman, L.; Friedman, J.H.; Olshen, R.A.; and Stone, C.J. 1998. Classification and Regression Trees. New York, New York: Chapman \& Hall/CRC Press.

BSC 2002. Guidelines for Developing and Documenting Alternative Conceptual Models, Model Abstractions, and Parameter Uncertainty in the Total System Performance Assessment for the License Application. TDR-WIS-PA-000008 REV 00 ICN 01. Las Vegas, Nevada: Bechtel SAIC Company. ACC: MOL.20020904.0002.

BSC 2004. General Corrosion and Localized Corrosion of Waste Package Outer Barrier. ANLEBS-MD-000003 REV 02. Las Vegas, Nevada: Bechtel SAIC Company. ACC: DOC.20041004.0001.

DOE 2005a. LP-SIII.10Q-BSC, Rev. 0, ICN 2. Models. Washington, D.C.: U.S. Department of Energy, Office of Civilian Radioactive Waste Management. ACC: DOC.20050623.0001.

DOE 2005b. LP-2.29Q-BSC, Rev. 0, ICN 2. Planning for Science Activities. Washington, D.C.: U.S. Department of Energy, Office of Civilian Radioactive Waste Management. ACC: DOC.20050912.0005.

Estill, J.C. 1998. "Long-Term Corrosion Studies." 2.2 of Engineered Materials Characterization Report. McCright, R.D., ed. UCRL-ID-1 19564 Volume 3 Rev.1.1. Livermore, California: Lawrence Livermore National Laboratory.

Hack, H.P. 1983. "Crevice Corrosion Behavior of Molybdenum-Containing Stainless Steels in Seawater." Materials Performance, 22, (6), 24-30. Houston, Texas: NACE International. TIC: 245826.

Helton, J.C. 1993. "Uncertainty and Sensitivity Analysis Techniques for Use in Performance Assessment for Radioactive Waste Disposal.” Reliability Engineering and System Safety, 42, (2-3), 327-367. Barking, Essex, England: Elsevier. 
Hofer, E. and Krzykacz, B. 1995. "On Benefits and Drawbacks of Customary Sensitivity Measures." Proceedings of the Symposium on Theory and Applications of Sensitivity Analysis of Model Output in Computer Simulation, SAMO. Belgirate(I), Italy.

Jones, D.A. 1992. Principles and Prevention of Corrosion. 1st Edition. New York, New York: Macmillan.

Mishra, S. and Knowlton, R.G. 2003. "Testing for Input-Output Dependence in Performance Assessment Models." Proceedings of the 10th International High-Level Radioactive Waste Management Conference (IHLRW), March 30-April 2, 2003, Las Vegas, Nevada. Pages 882-887. La Grange Park, Illinois: American Nuclear Society.

NRC 2001. 10 CFR Part 63. Disposal of High-Level Radioactive Wastes in a Geologic Repository at Yucca Mountain, Nevada. U.S. Federal Register, Vol. 66, p. 55732.

Payer, J.H. 2004. Corrosion Resistance of Alloy 22. Presented to: Nuclear Waste Technical Review Board, May 18-19, 2004. Washington, D.C.: U.S. Department of Energy, Office of Civilian Radioactive Waste Management. ACC: MOL.20040629.0421 (or http://www.nwtrb.gov/meetings/may\%202004/payer.pdf) 